\title{
Por uma sexualidade livre à luz de Foucault
}

\author{
For a free sexuality in the light of Foucault
}

\author{
Juliana Ortegosa Aggio \\ Docente do departamento de filosofia da UFBA
}

Resumo: Esse ensaio é uma proposta e não uma simples análise ou interpretação de texto. Uma proposta de reflexão sobre a nossa prática sexual que possa nos servir como provocação. Uma proposta que aventa a seguinte hipótese à luz das obras de Foucault sobre a sexualidade: se a relação sexual é sempre uma relação de poder, então há espaço para o exercício da liberdade, visto que a liberdade é condição de existência do poder enquanto a contraparte que o limita. Se isso for verdade, a questão da possibilidade está resolvida. Todavia, não basta demonstrar a possibilidade, é preciso compreender como, de fato, ela se efetiva. Veremos como a aposta de Foucault nos prazeres e corpos enquanto o contra-ataque ao dispositivo de sexualidade é posta em cheque por Butler, mas defendida por Oskala. Ambas parecem ter, em alguma medida, razão e a solução de Foucault pode ser reinterpretada a partir da possibilidade de se vivenciar uma sexualidade livre para além da mera liberação sexual.

Palavras-chave: Sexualidade, liberdade, Foucault, Butler

Abstract: This essay is a proposal and not a simple text analysis or interpretation. A proposal for reflection on our sexual practice that can serve as a provocation. A proposal that raises the following hypo- 
thesis in light of Foucault's works on sexuality: If sexual intercourse is always a power relationship, then there is room for the exercise of freedom, since freedom is a condition for the existence of power as the counterpart that limits it. If this is true, the question of possibility is resolved. However, it is not enough to demonstrate the possibility, it is necessary to understand how, in fact, it is realized. We will see how Foucault's bet on pleasures and bodies as the counterattack to the sexuality dispositive is put in check by Butler, but defended by Oskala. Both seem to be, to some extent, right and Foucault's solution can be reinterpreted from the possibility of experiencing a free sexuality beyond mere sexual liberation.

Key-words: Sexuality, freedom, Foucault, Butler

Desde os anos 1930, sabemos que todo fascismo mobiliza o ressentimento daqueles que fazem de tudo para não serem afetados pela circulação da sexualidade. Como se a sexualidade livre fosse colocar o corpo social em estado

de degenerência e degradação (Vladimir Safatle, Idiotas Inúteis, FSP 17.05.19)

Ste ensaio pode ser uma proposta para uns, uma provoca-
ção para outros. De toda sorte, não é uma tese, uma análise, uma interpretação de texto, mas, antes, uma proposta de reflexão sobre a nossa prática sexual, que aventa a seguinte hipótese à luz das obras de Foucault sobre a sexualidade: se a relação sexual é uma relação de poder, então haveria espaço para o exercício da liberdade no interior mesmo de nossa prática sexual? Ora, se a liberdade é condição de existência do poder enquanto a contraparte que o limita, então a questão da possibilidade está resolvida: a sexualidade poderá ser vivida como um jogo aberto entre sujeitos livres. Todavia, o problema permanece. Se o poder não apenas reprime, mas sobretudo produz a sexualidade, se os nossos corpos, prazeres e desejos estão desde sempre imersos no poder, se o poder age sobre o corpo e dentro do corpo, então da superfície de nossa pele aos recônditos de nosso inconsciente, onde restaria espaço para a 
liberdade? Em outras palavras: neste jogo agonístico entre liberdade e poder, o que seria vivenciar a liberdade sexual?

Comecemos decifrando a intrincada relação liberdade-poder.

\section{A metáfora do chuveiro: o circuito liberdade-poder}

Gostaria de fornecer uma metáfora útil, embora inusitada, para compreender a relação entre liberdade e poder: a metáfora do chuveiro ${ }^{35}$. A liberdade opera como um resistor de um chuveiro. Há, no chuveiro, um resistor e não uma resistência, como se costuma dizer. A resistência é, em verdade, a oposição que um corpo oferece à passagem de corrente elétrica, ou seja, é a capacidade que um corpo tem de dificultar os movimentos dos elétrons. O resistor é um componente que transforma energia elétrica em térmica e que também opera como resistência para preservar o chuveiro e evitar um curto-circuito em caso de excesso de energia elétrica. Se o resistor não der conta de transformar a energia elétrica em térmica porque a intensidade de energia é maior do que o que ele pode suportar, então ele atua como resistência. O resistor, portanto, exerce uma dupla função: (i) positiva: de transformar a energia elétrica em térmica e (ii) negativa: de barrar o excesso de energia elétrica. Analogamente, no circuito poder-liberdade, a liberdade atua como um resistor: ela transforma, desdobra, desvia, desconfigura, multiplica, ramifica, subverte as determinações vindas do poder ou, caso sejam excessivas, ela atua como barragem, obstáculo, limitação, resistência. A liberdade, portanto, atua antes como um princípio subversivo, desviante, transformador, criador de novas subjetividades do que pura e simples oposição ao poder. É resistência ao avanço do poder e à possibilidade de se instaurar um estado de dominação, mas sobretudo subversão do poder e transformação no e pelo poder. A resistência entra em cena em situação de urgência, para evitar que o poder extrapole o seu limite e se torne estado de dominação. A relação liberdade-poder é circular, é um circuito de mão-dupla:

35 Esse exemplo é inspirado no título do livro da poeta Marília Garcia, Um teste de resistores. 
um determinando o outro. A liberdade opera como um resistor que transforma e que resiste ao poder. Resiste, se for necessário, para que o circuito não se torne uma linha verticalizada de cima para baixo, estagnada entre dominador e dominado. Mas a função essencial da liberdade é transformar o poder, testar seus limites, provocar, desviar suas determinações, fissurar sua malha, desconfigurar sua ordem, subverter, enfim, transformar suas verdades em outras verdades, suas regras em outras regras, como a energia elétrica é transformada em térmica no chuveiro. Para tanto, é preciso água e a água, no circuito liberdade-poder, somos nós. A água, no chuveiro, é aquecida e nós, no circuito liberdade-poder, viramos sujeitos.

Em resumo, a liberdade é, para Foucault, a condição de existência do poder. Ela está imersa nos jogos de poder e lhe confere limitação, de sorte que tende a barrar a tendência de expansão ilimitada do poder. O poder, então, constitui o sujeito e, simultaneamente, fornece a condição para a sua desconstrução por meio do exercício da liberdade. Ou seja, para Foucault, o poder são relações em que um procura determinar a ação do outro, em que a sujeição significa tanto reiterar as normas, como formar ou produzir o sujeito de modo maleável, múltiplo, flexível, proliferativo e conflituoso. O poder é definido como um exercício, um ato, um modo de ação de uns sobre outros. A relação de poder é uma ação sobre a ação do outro por mecanismos mais ou menos coercitivos - por consentimento, persuasão, sedução, imposição, coerção e, no limite, por força, enquanto uma relação de violência que age sobre o corpo do outro. Em uma relação de poder, o outro não é anulado, coisificado, violentado em sua capacidade de agente. O outro é reconhecido como sujeito de ação, ou seja, está aberto ao outro um campo de possíveis respostas, reações, efeitos, invenções, inversões, desvios, mutações, subversões e mesmo resistências (FOUCAULT, 2014a, p. 132-3). Pode também haver violência em uma relação de poder, embora ela não seja em si violenta. É antes uma ação sobre ações, um governo sobre o outro do que um enfrentamento, um conduzir condutas em um campo mais ou menos aberto de possibilidades e por meio de mecanismos mais ou menos coercitivos (FOUCAULT, 2014a, p. 133). 
O que chamo de caráter subversivo da liberdade é o que filósofo chama de insubmissão da liberdade, de provocação incessante ao poder, de relativização do querer diante das determinações do poder (FOUCAULT, 2014a, p. 134). Ou seja, o outro, o conduzido, é conduzido em determinado momento e não em todo o tempo, e ele preserva sua liberdade na medida em que pode subverter aquilo que lhe fora determinado ou imposto, desejando outras ações imprevistas, desviantes, que dobram, desdobram e multiplicam as classificações sob as quais deve estar submissa a sua subjetividade.

Em um jogo agonístico de liberdade-poder, um procura determinar o outro, em meio a incitações e provocações recíprocas. Ao caráter determinador do poder, a liberdade responde com seu caráter provocador, subversivo. E, aqui, devemos compreender subversão como: (i) insubordinação contra a autoridade, as instituições, as leis, as regras aceitas pela maioria, (ii) transformação da ordem estabelecida, das regras e procedimentos de produção da verdade, (iii) ato ou efeito de transtornar ou perturbar o funcionamento "normal" das coisas e o comportamento regrado das pessoas.

Essa definição de liberdade como sendo tanto resistência como subversão do poder é importante para esclarecer que a liberdade não é antagônica ao poder e exercê-la não significa eliminar por completo o poder, ao contrário, é impossível ser livre fora de uma estrutura de poder. Em verdade, é impossível viver em sociedade sem estar imerso nas relações de poder. Não seria possível escapar por completo ou mesmo destruir as relações de poder. Como diz o filósofo: "Viver em sociedade é, de toda forma, viver de uma maneira que seja possível agir sobre a ação uns dos outros. Uma sociedade 'sem relações de poder' só pode ser uma abstração" (FOUCAULT, 2014a, p.135). Isso não significa, como bem aponta adiante, dizer "nem que estas < relações de poder> que são dadas são necessárias, nem que, de qualquer maneira, o poder constitua, no cerne das sociedades, uma fatalidade incontornável" (FOUCAULT, 2014a, p. 136). Ou seja, a liberdade só é possível no interior mesmo das relações de poder. 


\section{Liberação ou liberdade sexual?}

Se a liberdade é possível, cabe perguntar o que seria uma sexualidade livre? Será que, para viver uma sexualidade livre, é preciso a liberação dos desejos e práticas sexuais? Será que a nossa sexualidade precisa se libertar dos grilhões da repressão? O grande problema da sexualidade a ser pensado a partir das reflexões de Foucault não é o da liberação dos desejos e das práticas sexuais, como se nossa sexualidade precisasse se libertar dos grilhões da repressão ${ }^{36}$. Foucault denuncia essa solução fácil amparada no que ele chamou de hipótese repressiva (FOUCAULT, 2007a). É importante atentarmos para diferença entre liberação sexual e liberdade sexual, ou sexualidade liberta e sexualidade livre. Quando falamos em sexualidade liberta, a primeira pergunta que precisa ser respondida é: liberta ou liberada do quê? Mesmo que admitamos que a liberação da sexualidade de repressões morais restritivas e castradoras seja importante, isso não parece ser suficiente para se estabelecer práticas de liberdade sexual. Uma pessoa pode viver relações sexuais libertárias, sem pudores, sem restrições a regras morais, todavia, ainda assim não posso dizer que sua sexualidade é livre. Se o problema da sexualidade fosse a repressão moral e a submissão à interdição das leis e regras, essa seria a solução: liberação da sexualidade. O problema, todavia, consiste em definir as práticas de liberdade por meio das quais definimos e direcionamos nossa sexualidade e nosso prazer sexual. Nas palavras do filósofo:

O problema não seria antes tentar definir as práticas de liberdade através das quais seria possível definir o prazer sexual, as relações eróticas, amorosas e passionais com os outros? O problema ético

$36 \quad$ Como interpreta Butler: "Vale notar que, no História da Sexualidade, a função repressiva da lei é enfraquecida precisamente por ela se tornar o objeto de excitação e de investimento erótico. $\mathrm{O}$ aparelho disciplinar não reprime a sexualidade precisamente por ser ele mesmo erotizado, tornando-se ocasião para a incitação da sexualidade e, portanto, anulando seus próprios objetivos repressivos" (2017, p. 109). É bem verdade que há uma retroalimentação prazer/poder na medida em que ocorre a sensualização do poder e o aumento do prazer, ou seja, o poder se alimenta e se expande do prazer em exercer-se sobre a sexualidade, escrutinando a intimidade sexual em seus detalhes confessionais, e o prazer se maximiza por ter que escapar do poder (FOUCAULT, 2007a, p. 52-3). Todavia, não se deve assumir, como fez Butler, que a faceta repressora do poder fora anulada, mas apenas enfraquecida, secundarizada. 
da definição das práticas de liberdade é, para mim, muito mais importante do que a afirmação, um pouco repetitiva, de que é preciso liberar a sexualidade ou o desejo (FOUCAULT, 2017, p. 260).

Em poucas palavras, a liberação é necessária em estados de absoluta dominação e opressão, mas não é suficiente para se viver a liberdade sexual.

É preciso, por exemplo, se libertar de uma relação de abuso sexual, de absoluto constrangimento do outro, de coisificação do outro para que ele seja um objeto de prazer. Um exemplo dado pelo filósofo ${ }^{37}$ de liberação é justamente o da sexualidade da mulher em relação à dominação do marido com sua moral opressiva falocêntrica e heteronormativa. Neste caso, a liberação da sexualidade da mulher em relação à dominação masculina é necessária, mas não suficiente para a sua liberdade sexual. Viver a liberdade sexual implica compreender que a "liberação não faz surgir o ser feliz e pleno de uma sexualidade na qual o sujeito tivesse atingido uma relação completa e satisfatória. A liberação abre um campo para novas relações de poder, que devem ser controladas por práticas de liberdade" (FOUCAULT, 2017, p. 260-1).

Em outras palavras, tomemos cuidado para não nos iludirmos com a hipótese repressiva e sua solução libertadora, como se bastasse libertar o desejo para se viver uma sexualidade plena, completa e satisfatória. Há, por detrás da libertação, uma mistificação sobre a possibilidade de se viver plenamente a sexualidade, uma sexualidade sem as amarras do "poder repressor". Coloco "poder repressor" entre aspas porque, bem sabemos, o poder é antes produtor da sexualidade do que repressor.

Em suma, a liberação do desejo é necessária em situações de dominação. A liberdade sexual, por sua vez, é saber "como se conduzir eticamente nas relações de prazer com os outros" (FOUCAULT, 2017, p. 261). E o que Foucault quer dizer com isso? Que a relação sexual pode ser vivida não como dominação, mas como relação de poder controlada pela liberdade de modo a impedir que ela se torne um estado de dominação. Em verdade, toda relação de poder é uma relação de ação sobre

$37 \quad$ FOUCAULT, 2017, p. 261. 
a ação do outro que deixa aberta a possibilidade de inversões, desvios, resistências e subversões entre aquele que conduz e aquele que é conduzido numa dada relação de poder.

Brevemente, podemos dizer que poder é distinto de dominação. O poder são relações móveis e flexíveis entre indivíduos a serem exercidas em diversas situações, por exemplo, as relações sexuais, familiares, pedagógicas, médicas, no corpo político; enfim, toda relação em que um procura direcionar a ação do outro é uma relação de poder para o filósofo ${ }^{38}$. Já a dominação deve ser entendida como um estado de cristalização das relações de poder, ou seja, quando essas relações se tornam imóveis e fixas, assimétricas e violentas. No caso do estado de dominação, o outro é coisificado e violentado, sendo necessária a libertação para que surja a possibilidade de liberdade. As práticas de liberdade, neste caso, ou não existem ou são bastante restritas e limitadas.

Quanto mais livre for a relação de poder, mais móvel e reversível; quanto menos livre, mais estagnada em polos de dominação (dominador/dominado). A liberdade opera enquanto um correlato, um contrapeso, uma contramedida do poder, condição mesma da existência do poder, pois que controla as relações de poder para que essas não se transformem naquilo para o qual tendem: estados de dominação.

Quando a relação sexual não é um estado violento de dominação, temos então uma relação de poder que se exprime no ato sexual e se há poder, há, necessariamente, liberdade. No jogo poder-liberdade, os parceiros se determinam de forma dinâmica e flexível: um determina o prazer do outro, alternando-se assim como que em polos de condutor e de conduzido, ora cedendo ao prazer do outro e tendo prazer com o prazer do outro, ora resistindo ou subvertendo e tomando à frente, passando assim ao polo de condutor.

$38 \quad$ Com diz o filósofo: "Quero dizer que, nas relações humanas, quaisquer que sejam elas - quer se trate de comunicar verbalmente, como o fazemos agora, ou se trate de relações amorosas, institucionais ou econômicas -, o poder está sempre presente: quero dizer, a relação em que cada um procura dirigir a conduta do outro" (FOUCAULT, 2017, p. 270). 
Em suma, quais são os problemas de se apostar na liberação sexual para se viver uma sexualidade livre? Primeiro, não fazer a distinção elementar entre liberação sexual e liberdade sexual. Segundo, liberar o desejo sexual é antes alimentar o próprio dispositivo de sexualidade do que resistir e subvertê-lo. $\mathrm{O}$ dispositivo de sexualidade cria o desejo do sexo, torna o sexo desejável ao criar a vontade de sabê-lo. Assim, dizer sim ao sexo não é recusar o poder, é dizer sim ao dispositivo de sexualidade:

Com a criação deste elemento imaginário que é 'o sexo', o dispositivo de sexualidade suscitou um de seus princípios internos de funcionamento mais essenciais: o desejo do sexo - desejo de tê-lo, de aceder a ele, de descobri-lo, liberá-lo, articulá-lo em discurso, formulá-lo em verdade. Ele constituiu 'o sexo' como desejável. E é essa desirabilidade do sexo que fixa cada um de nós à injunção de conhecê-lo, de descobrir sua lei e seu poder; é essa desirabilidade que nos faz acreditar que afirmamos contra todo o poder os direitos de nosso sexo quando, de fato, ela nos vincula ao dispositivo de sexualidade que fez surgir, do fundo de nós mesmos, como uma miragem onde acreditamos reconhecer-nos, o brilho negro do sexo" (FOUCAULT, 2007a, p. 171).

Logo, liberar o desejo pelo sexo significa jogar o jogo do dispositivo de poder que produz e incita o próprio desejo de saber o sexo. Por isso, nas palavras do filósofo:

Não acreditar que dizendo-se sim ao sexo se está dizendo não ao poder; ao contrário, se está seguindo a linha do dispositivo geral da sexualidade. É com relação à instância do sexo que devemos nos liberar se, por uma inversão tática dos diversos mecanismos da sexualidade, quisermos opor às captações do poder os corpos, os prazeres, os saberes, em sua multiplicidade e sua possibilidade de resistência. Contra o dispositivo de sexualidade, o ponto de apoio do contra-ataque não deve ser o sexo-desejo, mas os corpos e os prazeres (FOUCAULT, 2007a, p. 173) ${ }^{39}$.

Ou seja, acreditar que no sexo, no desejo pelo sexo está a nossa "libertação" é um dos principais ardis do dispositivo

$39 \quad$ No original : « Ne pas croire qu 'en disant oui au sexe, on dit non au pouvoir; on suit au contraire le fil du dispositif général de sexualité. C'est de l'instance du sexe qu'il faut s'affranchir si, par un retournement tactique des divers mécanismes de la sexualité, on veut faire valoir contre les prises du pouvoir, les corps, les plaisirs, les savoirs, dans leur multiplicité et leur possibilite de résistance. Contre le dispositif de sexualité, le point d'appui de la contre-attaque ne doit pas être le sexe-désir, mais les corps et les plaisirs ». 
de sexualidade, que nos faz crer que o sexo está sob forte repressão e precisa ser liberado em ato e em palavras, sobretudo em palavras, pela confissão. Ao invés de acreditar que o desejo pelo sexo precisa ser liberado das repressões, é preciso inventar outras economias dos corpos e dos prazeres que escapem aos ardis do dispositivo de poder que produz a nossa sexualidade, os nossos desejos e prazeres sexuais, os gestos e maneiras de ser dos nossos corpos. Nos volumes II e III da História da Sexualidade, Foucault procurará nas práticas dos gregos e romanos antigos exemplos de outras economias, outros modos de se viver a sexualidade e o prazer ${ }^{40}$. De todo modo, a pergunta permanece: como nós, que estamos submetidos ao dispositivo de sexualidade, podemos viver uma sexualidade livre, criativa, flexível, múltipla?

Essa é a única pista que o filósofo nos fornece na História da Sexualidade, vol. I, sobre a possibilidade de resistir ao dispositivo de sexualidade. A pista é enxuta o suficiente para nos causar certo incômodo, assim como causou a um entrevistador $^{41}$ que lhe perguntou sobre este ponto e obteve a seguinte resposta de Foucault:

É difícil responder a esta pergunta, pois até para mim mesmo isso não está muito claro; porém, acredito poder dizer o seguinte: o slogan lançado pelos movimentos de liberação da sexualidade - que é "Liberem o desejo" - parece não só carecer de força de persuasão, mas também ser um pouco perigoso, pois este desejo que se exige ser liberado é na verdade apenas um elemento constitutivo da sexualidade, sendo apenas aquilo que foi diferenciado do resto na forma de desejos carnais pela disciplina da Igreja Católica e pela técnica de exame de consciência (...). Uma coisa da qual não se fala nessa

$\overline{40} \quad$ O último parágrafo do volume I da História da Sexualidade já nos indica que esse é o caminho: "devemos pensar que um dia, talvez, numa outra economia dos corpos e dos prazeres, já não se compreenderá muito bem de que maneira os ardis da sexualidade e do poder que sustêm seu dispositivo conseguiram submeter-nos a essa austera monarquia do sexo, a ponto de votar-nos à tarefa infinita de forçar seu segredo e de extorquir a essa sombra as confissões mais verdadeiras" (FOUCAULT, 2007a, p. 174).

${ }_{41}$ Watanabe, em uma entrevista em Tóquio, em 1978, pergunta o seguinte: "Em A vontade de saber, o senhor escreveu que é 'no corpo e no prazer' que se poderia encontrar um apoio, talvez antagônico, a respeito do sexo encarnando o desejo. Porém o próprio corpo é ambíguo, e podemos pensá-lo como um dispositivo atravessado pelo poder" (2017, p. 30). 
perspectiva é o prazer. Neste sentido, escrevi que se quiserem se libertar da ciência do sexo deveriam encontrar sustentação no prazer, no maximum de prazer $(2017, \text { p. } 30-31)^{42}$.

Ou seja, liberar o desejo significa cair na armadilha do dispositivo de sexualidade, significa fazer uso da técnica da confissão, desde a Idade Média, e que continua na modernidade com a psicanálise. Confessar os desejos sexuais não faz senão alimentar a produção de discursos sobre a sexualidade, constituindo uma verdadeira ciência da sexualidade (chamada por Foucault de scientia sexualis), e assim corroborar com o controle do poder sobre a sexualidade. A via de resistência estaria no prazer e não no desejo. Todavia, se o poder procurou estimular a intensidade dos prazeres, como se poderia propor a maximização do prazer como uma prática de resistência ao dispositivo de sexualidade? Talvez Foucault não tenha sido feliz nessa formulação ou tenhamos que compreender o que significa maximização do prazer. Possivelmente, não se trata apenas de aumentar em quantidade o prazer - isso o dispositivo de sexualidade já o faz -, mas em permitir a vivência de novos prazeres, novas sensações e práticas sexuais que são intensas em quantidade e qualidade, porque desviam e subvertem as relações de poder já estabelecidas na sexualidade. A maximização, talvez, deva ser compreendida como multiplicação, prolifera-

$42 \quad$ Citação completa: "É difícil responder a esta pergunta, pois até para mim mesmo isso não está muito claro; porém, acredito poder dizer o seguinte: o slogan lançado pelos movimentos de liberação da sexualidade - que é "Liberem o desejo" - parece não só carecer de força de persuasão, mas também ser um pouco perigoso, pois este desejo que se exige ser liberado é na verdade apenas um elemento constitutivo da sexualidade, sendo apenas aquilo que foi diferenciado do resto na forma de desejos carnais pela disciplina da Igreja Católica e pela técnica de exame de consciência. Assim, desde a Idade Média, se começou, no mundo do cristianismo, a analisar os elementos do desejo, e pensou-se que este constituía precisamente o prenúncio do pecado, e sua função era reconhecida não apenas nos atos sexuais, mas também em todos os campos do comportamento humano. O desejo era, assim, um elemento constitutivo do pecado. E liberar o desejo nada mais é do que você próprio decifrar o inconsciente, como os psicanalistas e muito antes a disciplina prática da confissão católica puseram em prática. Uma coisa da qual não se fala nessa perspectiva é o prazer. Neste sentido, escrevi que se quiserem se libertar da ciência do sexo deveriam encontrar sustentação no prazer, no maximum de prazer" (FOUCAULT, 2017, p. 30-1). 
ção das formas de prazer e não como simples aumento da intensidade do prazer. O ponto é que a pergunta permanece: em que condições essa proliferação poderia ocorrer? Qual relação sexual possibilitaria essa proliferação de prazeres subversivos?

A resposta a essa pergunta parece se encontrar na entrevista Ética do cuidado de si como prática da liberdade. A sexualidade enquanto prática da liberdade é uma espécie de jogo aberto estratégico em que um exerce poder sobre o outro, um seduz o outro de modo a determinar a sua ação e o seu prazer, um jogo aberto o suficiente para permitir inversões e mutações do lugar de poder ${ }^{43}$. Novamente, a sexualidade livre é vivenciada como um jogo aberto entre sujeitos livres, um tentando determinar a conduta do outro, sobretudo por persuasão e sedução. Quanto mais livres forem os sujeitos, mais haverá desejo de um agir sobre o outro, de um determinar a ação e o prazer do outro. Quanto mais aberto o jogo, mais atraente e fascinante, portanto, mais possibilidade de os parceiros sexuais vivenciarem novas formas de prazer: o maximum de prazer ${ }^{44}$.

Em que pese a tendência de vermos aqui a solução do problema sobre a sexualidade livre, permanece a pergunta: mas como esses múltiplos prazeres e jeitos de corpos subvertem o poder que vem não do parceiro sexual, mas das normas que produzem os modos de se sentir prazer e se expressar com o corpo? O poder produz o desejo, e não produz os corpos e os prazeres? O que dos corpos e prazeres escapa mais ao poder do que o desejo?

$43 \quad$ Nas palavras de Foucault, contrariando a concepção sartriana de que o poder seria um mal: "Sabe-se muito bem que o poder não é um mal! Considerem, por exemplo, as relações sexuais ou amorosas: exercer poder sobre o outro, em uma espécie de jogo estratégico aberto, em que as coisas poderão se inverter, não é o mal; isso faz parte do amor, da paixão, do prazer sexual" (FOUCAULT, 2017, p. 278).

$44 \quad$ Nas palavras do filósofo: "em uma sociedade como a nossa - isso é muito evidente, por exemplo, nas relações familiares, nas sexuais ou afetivas -, os jogos podem ser extremamente numerosos e, consequentemente, o desejo de determinar a conduta dos outros é muito maior. Entretanto, quanto mais as pessoas forem livres umas em relação às outras, maior será o desejo tanto de umas como de outras de determinar a conduta das outras. Quanto mais o jogo é aberto, mais ele é atraente e fascinante" (FOUCAULT, 2017, p. 280). 


\section{O contra-ataque dos corpos e prazeres}

Em seu ensaio, Revisiting Bodies and Pleasure, Butler procura compreender justamente a enigmática proposta do filósofo para resistirmos ao dispositivo de sexualidade fazendo uso não do sexo-desejo, mas dos corpos e prazeres como contra-ataque. Butler acredita que

a frase 'corpos e prazeres' sustentava a possibilidade de corpos não marcados, corpos que não fossem mais pensados ou experimentados em termos de diferença sexual ${ }^{45}$, e prazeres que fossem difusos, possivelmente sem nome, intensos e estimulantes, prazeres que tomassem o corpo como um todo, atuando desde sua superfície até sua profundidade (BUTLER, 1999, p. 11) ${ }^{46}$.

Essa proposta, para Butler, coloca o desejo como presa fácil do sistema de poder, como um meio de atuação do mecanismo heteronormativo, enquanto os corpos e prazeres estariam do lado da resistência possível. A pergunta que Butler faz a Foucault é a seguinte: qual é o custo de se separar a análise dos corpos e prazeres da análise do sexo e do desejo?

Segundo a filósofa, a proposta de Foucault nos chega como uma injunção, uma prescrição, o que devemos e não devemos fazer, ou seja, devemos apostar nos corpos e prazeres e não no sexo-desejo como contra-ataque ao dispositivo de sexualidade. Os corpos e os prazeres não vigoraram como o motor do dispositivo de sexualidade, que se encontra na vontade de saber o sexo, no desejo-sexo, e, por isso, podem atuar enquanto resistência. A pergunta feita, com razão, por Butler é a seguinte: "Estes corpos, esses prazeres, de onde eles vêm, e em que agência consistem, se eles são a agência que contraria o regime de sexo-desejo?" (1999, p. 14). Em outros termos, a pergunta posta é: quem rompe? Quem é capaz de resistir ao dispositivo de sexualidade ou ao regime sexo-desejo? Onde ocorre a ruptura? Por quais meios? A pergunta de fundo e que põe em cheque a injunção de Foucault aos corpos e prazeres é a seguinte: como os corpos e os prazeres poderiam resistir ao dispositivo de se$45 \quad$ A diferença sexual, para Butler, está vinculada a uma heterossexualização do desejo, baseada em uma lei aparentemente imutável, provavelmente a lei do complexo de Édipo, que é heteronormativa.

Todas as traduções do ensaio de Butler são minhas. 
xualidade se eles mesmos já são constituídos (derivados, em algum sentido) pelas regulamentações normativas discursivas? É como se o corpo pudesse ultrapassar, em alguma instância, a sua construção discursiva, como se ele fosse uma instância sempre incompleta ou cuja superfície escapasse ao discurso em alguma medida. O corpo seria como um princípio permanente de disrupção? Seria essa uma visão idealizada de corpo? (BUTLER, 1999).

Butler já havia criticado essa posição de Foucault em sua obra Problemas de gênero, em 1990, em sua análise sobre a sexualidade da hermafrodita Herculine Barbin, por lhe atribuir uma visão romanceada de seus prazeres, e por afirmar que a/o mesma/o se encontra num limbo feliz da não identidade. A crítica de Butler é que Foucault foi contraditório ao propor que Herculine seria uma exceção à lei imposta pela categoria do sexo, como se o seu sexo, corpo e prazeres não fossem produzidos nem regulados por lei alguma, mas estivessem "antes" ou "fora" da lei. Como se houvesse uma "proliferação de prazeres fora do contexto de inteligibilidade imposto pelos sexos unívocos na relação binária" (BUTLER, 2016, p. 169); como se a derrubada do "sexo" liberasse uma multiplicidade sexual primária, polimorfa, pré-discursiva, ou seja, uma multiplicidade de prazeres que não seria envolta no regime poder/saber. Todavia, como afirma Butler, sexualidade e poder, para Foucault, são coextensivos, logo, Herculine não poderia ser uma exceção a esse regime. A ambiguidade de seu sexo e de sua leitura sobre si é insolúvel e é, ela mesma, produzida pela lei. A lei proíbe e regula e, ao proibir e regular, produz o desejo, a sexualidade, enfim, a própria subjetividade. É o "fora" da lei que é produzido pela própria lei no caso de Herculine. A sua ambiguidade é a lei às avessas, uma vez que a lei "afastaria" a ambiguidade ao conceber o sexo como sendo unívoco e binário: ou seja, há apenas dois sexos e cada pessoa é ou de um ou de outro sexo. Não é aceitável pertencer aos dois, por isso a ambiguidade é proibida e, ao ser proibida, a própria ambiguidade do hermafroditismo é produzida pela categoria do sexo. É como se Foucault, aos olhos de Butler, tivesse caído na armadilha da hipótese repressiva, que ele mesmo deflagrou e recusou como sendo a melhor 
leitura da sexualidade na modernidade. Haveria em Herculine um sexo puro, "antes" da lei, que fora reprimido pelo binarismo. Butler (2016, p. 172) denomina esta concepção de "reificação metafísica da sexualidade múltipla".

A partir desta crítica, a filósofa formula o problema da possibilidade de uma sexualidade livre com maestria: "até que ponto o jogo é livre, seja ele concebido como multiplicidade libidinal pré-discursiva ou como multiplicidade discursivamente constituída?" (BUTLER, 2016, p. 176). Butler mostra, assim, que Foucault se contradiz ao conceber a sexualidade de Herculine como livre na sua multiplicidade pré-discursiva e, com base na própria teoria foucaultiana do dispositivo de sexualidade, ela certamente aposta na liberdade como uma multiplicidade discursivamente constituída de sexo, sexualidade e gênero.

Dois pontos devem ser levados em conta sobre essa crítica. Primeiro, Foucault não faz essa leitura de Herculine como um lugar de escape ao dispositivo de sexualidade, mesmo porque, o regime ao qual sua sexualidade está submetida é o do pastorado e não o do saber/poder moderno ${ }^{47}$. Segundo, acredito que possamos assumir uma multiplicidade discursiva dos prazeres e corpos como lugar de resistência e subversão ao poder, mas sem excluir a possibilidade de experiências não discursivas no corpo, que posteriormente serão traduzidas em discurso. Que fique claro que não discursivo não significa pré-discursivo, mas um lugar limite da linguagem e da inteligibilidade alcançado pelo corpo na fruição dos prazeres, dores, sensações extremas, êxtases, como veremos adiante.

Retomando o ensaio Revisiting Bodies and Pleasure, Butler nos diz que se contrapor ao sexo-desejo requer uma outra instância e o corpo seria essa outra instância ao atuar, por um lado, como superfície que recebe inscrições discursivas e, por outro, como resistência a tais inscrições (BUTLER, 1999, p. 14). Os corpos e prazeres podem nos transportar para uma dimensão anterior ou para além do poder regulatório da sexualidade, que, em algum sentido, supere o dispositivo de sexu-

47 Como sugere Duarte (2016), Butler não faz essa leitura porque, certamente, lhe faltou o acesso à versão francesa publicada na revista Arcadie. 
alidade. Mas como, por meio de qual técnica ou tática, seria possível superar ou reverter a sexualidade? Esse momento ou estágio não poderia, por sua vez, ser chamado de sexualidade, uma vez que o nome mesmo sexualidade designa o fenômeno em que o poder produz nossa sexualidade (BUTLER, 1999, p. 15). Neste ponto, Butler acaba por colocar em cheque a minha proposta de uma sexualidade livre, como se esses dois termos formassem um oxímoro, pois que, para ser livre, já não poderia ser sexualidade, ou que o seja em sentido figurado ou subversivo, ou mesmo por catacrese, como sugere Butler. Seria, talvez, mais apropriado falarmos em corpos e prazeres livres do que em uma sexualidade propriamente livre. Ora, mas devemos nos ater ao sentido de liberdade que estou trazendo aqui. A liberdade não é desvinculação absoluta do poder, não escapa inteiramente ao seu aspecto regulatório e normativo. A liberdade é resistência e subversão às determinações do poder, portanto, ocorre em diálogo com o poder, como seu contraponto e jamais como uma instância para além do poder. Quando se cria a sexualidade, cria-se um dispositivo de poder que pode ser subvertido, criam-se os limites e as normas para os comportamentos sexuais, cria-se também com isso a possibilidade de transgredir tais limites e vivenciar certa liberdade sexual. Tendo em vista essa acepção de liberdade, parece fazer sentido propor uma sexualidade livre enquanto uma sexualidade que se constitui no e pelo poder ao subvertê-lo.

A crítica se esboça agora em outra demanda: enquanto o sexo é performatizado segundo um certo regime de verdade, os corpos e prazeres poderiam assumir um sentido extra-moral ao romper com tal regime de verdade? (BUTLER, 1999, p. 16). Ademais, pergunta Butler (idem, p. 17), essa ruptura não geraria um novo regime de verdade, uma nova normatização e regulamentação da sexualidade? Mais do que isso: essa nova normatização não estaria permeada por aquela a que se recusa e, ao mesmo tempo, lhe serve de fundamento? Ou seja, a ruptura pressupõe o rompido em seu interior em alguma medida. Não há ruptura do nada, quando se rompe rompe-se com algo e esse algo mesmo funda ou dá fundamento à própria ruptura. Logo, os corpos e prazeres ou qualquer que seja o nome que se dê ao 
rompido nunca rompe por completo, mas carrega em si algo do que se rompeu; algo do "sexo-desejo" permeia os corpos e prazeres na leitura da filósofa ${ }^{48}$. Eis que Butler expressa sua recusa à prescrição feita por Foucault: "não faria sentido dividir e opor corpos e prazer, de um lado, e 'sexo-desejo' do outro, se a normatividade do último continua a assombrar e estruturar as modalidades vividas do primeiro" (BUTLER, 1999, p. 18).

Endossando a crítica de Butler, podemos dizer que Foucault enfatiza que a técnica de confissão adotada no regime disciplinar procura controlar inteiramente o desejo, mas também diz que a sexualidade não é senão um dispositivo que incide sobre os corpos e prazeres. Por um lado, a estratégia confessional é uma técnica utilizada para fazer com que todo o seu desejo seja dito, ou seja, para procurar fazer de todo seu desejo um discurso. Isso significa dominar, orientar, controlar, modificar o próprio desejo, ou seja, escrutinar a subjetividade até seus liames mais profundos, seus recônditos mais secretos de modo a possuir inteiramente o sujeito (FOUCAULT, 2007a, p. 25-29). Por outro, em sua definição de sexualidade, corpos e prazeres estão presentes como objetos aos quais incide o poder e não como um lugar de resistência:

A sexualidade é o nome que se pode dar a um dispositivo histórico: não à realidade subterrânea que se apreende com dificuldade, mas à grande rede da superfície em que a estimulação dos corpos, a intensificação dos prazeres, a incitação ao discurso, a formação dos conhecimentos, o reforço dos controles e das resistências, encadeiam-se uns aos outros, segundo algumas grandes estratégias (FOUCAULT, 2007a, p. 116-7, grifos meus).

O dispositivo de sexualidade funciona com técnicas móveis, polimorfas e conjunturais do poder, opera por meio de formas de domínio e de controle, em que o que importa são

\footnotetext{
48 A crítica de Butler, como ela mesma diz, acompanha os estudos queer e feministas e tem como pano de fundo a seguinte questão: é possível haver uma visão emancipada depois da crítica à emancipação? Essa visão pode ou deve estar baseada na ruptura com o passado que insiste em retornar ao que fora reprimido? Enfim, é possível haver uma disrupção dessa visão precisamente com o que ela deveria repudiar? A resposta de Butler é incisiva: não é possível e uma visão assim é utópica ou fruto do que ela chama de "ruptura utópica" (utopian break) (BUTLER, 1999, p. 18).
} 
"as sensações do corpo, a qualidade dos prazeres, a natureza das impressões" (FOUCAULT, 2007, p. 117); por fim, um dispositivo que tem como objeto o corpo que produz e consome, e como estratégia não o reproduzir, mas o proliferar, inovar, inventar, penetrar nos corpos de maneira cada vez mais detalhada (poder individualizante) e controlar a população (poder totalizante). Novamente, Foucault define a sexualidade como "o conjunto dos efeitos produzidos nos corpos, nos comportamentos, nas relações sociais, por certo dispositivo pertencente a uma tecnologia complexa" (FOUCAULT, 2007, p. 139. grifos meus). Em suma, o poder parece incidir tanto sobre o desejo, sobretudo pelo mecanismo da confissão, como sobre os corpos e prazeres, produzindo modos de sentir prazer e de se relacionar com o próprio corpo.

Por outro lado, Foucault, em uma entrevista de 1978 denominada $O$ saber gay, nos dá uma pequena pista, ainda não de todo convincente, da razão pela qual a aposta deve ser feita no prazer e não no desejo. O prazer, diz ele, "escapa às conotações médicas, naturalistas e que carregam junto com elas a noção de sexualidade. Não há, no fim das contas, prazer 'anormal', não há 'patologia' do prazer" (FOUCAULT, 2015, p. 5). A aposta do filósofo parece ser a seguinte:

Ao utilizar a palavra prazer, que no limite não quer dizer nada, que está ainda suficientemente vazia de conteúdo e virgem de utilização possível, não tomando por prazer, afinal, senão um acontecimento, um acontecimento que se produz, e que se produz, diria eu, fora do sujeito, ou no limite do sujeito, ou entre dois sujeitos, nessa coisa qualquer que não é nem do corpo nem da alma, nem exterior nem interior, quem sabe teríamos, ao procurar refletir sobre essa noção de prazer, um meio de evitar toda a armadura psicológica e médica que a noção tradicional de desejo carregava? (FOUCAULT, 2015, p. 7).

A opção pelo prazer enquanto acontecimento seria uma precaução metodológica para se evitar o desejo enquanto atributo de um sujeito a ser analisado e enquadrado na produção médico-psicanalítica, ou seja, enquanto o desejo operaria como um atributo de um sujeito a ser analisado, capturado e produzido pelo poder, o prazer teria essa característica volátil, flexível, múltipla, que não permite que se estabeleça um sujeito de prazer como estabelecemos correntemente um sujeito de desejo. Trocan- 
do em miúdos, sente-se prazer, o prazer ocorre, é um acontecimento entre sujeitos, um entre o dito e o não dito, mas não é propriamente de um sujeito, enquanto o desejo é de um sujeito e, mais ainda, revela o que esse sujeito desconhece de si mesmo:

O essencial é essa noção de acontecimento não atribuído e não atribuível a um sujeito. Ao passo que a noção, digamos, novecentista de desejo é primária e fundamentalmente vinculada a um sujeito. Não é um acontecimento, é uma espécie de permanência característica de acontecimentos de um sujeito que, nesse sentido, permite precisamente fazer uma análise do sujeito, uma análise médica do sujeito, uma análise judiciária do sujeito. Dize-me qual é teu desejo, eu te direi quem és como sujeito" (FOUCAULT, 2015, p. 7-8).

Em verdade, Butler acredita que Foucault tenha abandonado essa ruptura com o sexo-desejo no segundo volume da História da Sexualidade. A pergunta sobre a genealogia do sujeito de sexualidade conduz à dificuldade de ter de se buscar a genealogia do sujeito de desejo, ou seja, para compreender como o sujeito se reconhece como sujeito de uma sexualidade é "indispensável distinguir previamente a maneira pela qual, durante séculos, o homem ocidental fora levado a se reconhecer como sujeito de desejo" (FOUCAULT, 2007b, p. 11). Para analisar o sujeito de desejo será necessário, por sua vez, analisar o que é designado como sujeito, ou seja, "pesquisar quais são as formas e as modalidades da relação consigo através das quais o indivíduo se constitui e se reconhece como sujeito" (idem, p. 11). O problema de se reconhecer como sujeito de uma sexualidade pressupõe compreender como o indivíduo se reconhece como sujeito de desejo de uma determinada sexualidade e, por sua vez, como se reconhece como sujeito. O rumo que parece tomar a sua investigação sobre a sexualidade o faz, segundo Butler, retornar à problemática do desejo, sem deixar de fazer a crítica em relação a ele. Ainda permanecem em aberto os problemas da estruturação normativa da sexualidade a partir da pressuposição de uma teleologia natural da heterossexualidade, como se as diferenças de gênero e de sexualidade, bem como o tipo de objeto de desejo fossem determinados com a finalidade de cumprir a heterossexualidade inscrita em nossa natureza (BUTLER, 1999, p. 19). Isso significa que, dentro do quadro normativo heterossexual, o indivíduo se reconhece en- 
quanto sujeito de uma sexualidade e de um determinado gênero ao se submeter ao poder que opera por meio de constrições e controle, mas essa constrição também é produtiva, criando sexualidade e desejo. Por isso, ao invés de fazer a história dos corpos e prazeres, é preciso faz a história do sujeito de desejo e, mais ainda, do próprio sujeito, já que o sujeito é "tanto constituído pelo poder, como um ponto nodal na rearticulação e transformação do poder" (BUTLER, 1999, p. 20).

De fato, essa é a proposta do Foucault nos anos 80. Talvez, e nesse ponto estou de concordo com Butler. A restrição aos corpos e prazeres para o ponto de apoio do contra-ataque não soa convincente: deveria, a meu ver, se considerar o sujeito por inteiro, com seus desejos, prazeres, corpos, pensamentos e ações. O sujeito, como um todo, é permeado pelo poder e sua constituição é, em grande medida, efeito do poder. Ser efeito do poder é justamente o que fornece as condições mesmas de ruptura com o poder, e essa é a via da liberdade na constituição de si.

Todavia, ainda caberia retomar a proposição foucaultiana de contra-ataque ao dispositivo de sexualidade e investigar mais detidamente o seu sentido, propósito, validade. Segundo Oskala (2005), é preciso compreender a concepção foucaultiana de corpo para se decidir sobre esse dilema. É evidente que o corpo não poderia ser um lugar de pura passividade se se quer que ele possa atuar como resistência ao poder normatizante. Foucault teria adotado uma concepção de corpo experimental e não mais corpo como objeto de manipulação disciplinar, como em Vigiar e Punir (2005, p. 127). O próprio filósofo enfatiza a capacidade de contra-ataque do corpo diante dos efeitos do poder:

O domínio, a consciência de seu corpo não puderam ser adquiridos senão pelo efeito do investimento do corpo pelo poder (...). Mas, a partir do momento em que o poder produziu esse efeito, na própria linha de suas conquistas, emerge inevitavelmente a reivindicação de seu corpo contra o poder, a saúde contra a economia, o prazer contra as normas morais da sexualidade, do casamento, do pudor. $\mathrm{E}$, assim, aquilo pelo que o poder era forte se torna aquilo pelo que é atacado (FOUCAULT, 2014b, p. 259).

A batalha é contínua entre a via da liberdade e a do poder no corpo e, eu diria, concordando com Butler, também 
nos desejos, nos prazeres, nos pensamentos, nas ações, enfim, na subjetividade como um todo. Todavia, Oskala, defendendo a proposta de Foucault e se contrapondo a Butler, diz que a experiência sexual dos prazeres não pode ser inteiramente reduzida a significados discursivos, na medida em que o corpo, mesmo que constituído pelo poder discursivo, não estaria inteiramente submisso aos discursos científicos e às tecnologias disciplinares. Haveria, por assim dizer, um lugar privilegiado em nossa subjetividade que resistiria à inteira captação do discurso e do poder. Como ela diz, ao contrário do que pensa Butler: "o corpo sexual enquanto experimentação é capaz de multiplicar, distorcer e transbordar suas definições discursivas, classificações e coordenadas. O corpo-experiência pode conduzir a linguagem normal ao ponto em que ela falha, perde seu poder de definição, e mesmo de expressão. Isso, no entanto, não significa um retorno a um corpo pré-discursivo" (2005, p. 130) ${ }^{49}$. O corpo enquanto contestação, resistência, subversão estaria no limite da linguagem discursiva, em momentos em que a linguagem chega a seus confins, transborda a si mesma e se desavia diante de explosões de emoções, como quando os olhos reviram para trás em êxtase. Essas experiências limites vividas no corpo podem ser posteriormente traduzidas em linguagem discursiva. É como se o corpo, na experiência sexual, pudesse estar em uma região fronteiriça entre o dito e o não dito, entre a norma e o que ultrapassa a norma. Como diz Oskala (2005, p. 130): "O próprio processo de normatização define os limites para experiências normais, mas esses limites abrem possibilidades de transgressão que afirmam o potencial ilimitado do corpo".

Essa interpretação rebate o postulado de Butler de que o filósofo estivesse propondo um corpo pré-discursivo anterior ao corpo normatizado: um lugar idílico e utópico a ser resgatado do passado para o presente. Ao contrário, como não há liberdade sem poder e vice-versa, não poderia haver corpo subversivo sem corpo normatizado, como diz Oskala (2005, p. 131): "essa resistência, no entanto, não é um retorno a um corpo selvagem e natural, mas é a resistência possibilitada pelo poder normatizador", ou seja, "o poder-saber inscreve os limi-

49 Todas as traduções do livro de Oskala são minhas. 
tes das experiências normais, mas é exatamente a existência desses limites que possibilita sua transgressão" (idem, p. 132). O corpo não pode ser inteiramente determinado pelo poder, e suas experiências limites evidenciam que o corpo é capaz de distorcer, multiplicar, ultrapassar os significados, as definições e classificações vinculadas às experiências. Ou seja, as experiências de transgressão são "exteriores" (outsiders) ao constituírem o limite das normas e do inteligível. Nesse sentido, o corpo é capaz de prazeres indizíveis e ininteligíveis, e é o lugar de "permanente contestação das definições discursivas, valores e práticas normativas" (OSKALA, 2005, p. 132). Oskala conclui sua brilhante interpretação com a qual estou de acordo: a liberdade do corpo reside no fato de ele ser culturalmente "inscrito de maneira aberta a reinterpretações e múltiplos significados" (idem, p. 134), o que pode ser estendido para o entendimento da própria subjetividade.

\section{Conclusão}

Abertura à multiplicidade, experiência-limite, lugar híbrido, fronteiriço, ou melhor, jogo agonístico poder-liberdade constituem não apenas a nossa experiência sexual, mas todas as experiências que compõem a nossa subjetividade. Neste ponto, diria que o próprio desejo não estaria fora dessa dinâmica de opostos, nessa luta constante entre a normatização e a transgressão, a imposição e a resistência, a determinação e a subversão, enfim, entre o poder e a liberdade.

Por isso, abandonar o sexo-desejo como um lugar de resistência significa tão somente que investir na liberação do desejo pelo sexo é investir na vontade de saber o sexo, é alimentar a produção científica e normativa do sexo. Acreditar que o sexo está reprimido e precisa ser liberado significa alimentar o desejo pelo sexo, liberá-lo em palavras, fazê-lo objeto confessional: esse é o cerne do mecanismo do dispositivo de sexualidade. Todavia, o desejo de realizar práticas sexuais livres atravessa o nosso corpo e o modo como o experimentamos no ato sexual. Esse desejo pela liberdade sexual dialoga constantemente com as determinações do poder. Está, em parte, emaranhado no poder e, em 
parte, resiste aos padrões heteronormativos, subverte injunções edipianas, joga o jogo do poder-liberdade, sendo constituído no circuito mesmo desse jogo agonístico. Não se deve apostar no desejo-sexo enquanto vontade de saber sobre o sexo, mas não se trata de abandonar o desejo por completo. O desejo, assim como o corpo, opera nesse lugar fronteiriço e híbrido que subjaz e também subverte as normas. Potencializar ou maximizar o desejo, o prazer e o corpo significa procurar vivenciar múltiplas experiências e proliferar os tipos de desejos e prazeres, os modos de se desejar e sentir prazer, os jeitos de corpo e os modos de estar ou vivenciar o próprio corpo nas experiências sexuais. $\mathrm{O}$ viés da liberdade passa por aí: procurar as condições de se viver uma sexualidade livre com seus parceiros sexuais e consigo mesmo, flexibilizando e abrindo ao máximo os jogos de poder-liberdade das relações sexuais de modo a criar um campo difuso que ora reitera, ora transgride as normas.

É mais do que evidente que há espaço para a liberdade sexual, para além da mera liberação sexual, e esse espaço não poderia residir em uma ciência ou conhecimento científico, que estão antes a serviço da própria vontade de saber sobre o sexo. A arte de viver, as técnicas de cuidado de si, a atitude crítica nos conduzem para o viés da liberdade, enquanto a ciência para o viés do poder normatizador. Essas conclusões são possíveis a partir das reflexões do filósofo nos anos 80, sobretudo nas entrevistas Ética do cuidado de si como prática da liberdade (1984) e Sexo, Poder e a Política da Identidade (1982). Na primeira, ele nos mostra que a condição para se viver uma sexualidade livre é que os parceiros vivam a relação sexual como um jogo poder-liberdade o mais aberto e flexível possível, com alternâncias frequentes entre condutor e conduzido. Na segunda entrevista, ele nos diz que a sexualidade

faz parte da liberdade de que gozamos neste mundo. A sexualidade é algo que nós criamos nós mesmos - ela é nossa própria criação, muito mais do que a descoberta de um aspecto secreto de nosso desejo. Devemos compreender que, com nossos desejos, através deles, se instauram novas formas de relações, novas formas de amor e novas formas de criação. O sexo não é uma fatalidade; ele é uma possibilidade de chegar a uma vida criadora (FOUCAULT, 2014a, p. 251). 
Como a experiência sexual não pode ser inteiramente definida discursivamente e determinada pelas normas, a dimensão da liberdade se encontra na possibilidade da insurgência, resistência e subversão, ainda que os desvios ou deslocamentos ocorram no e pelo poder. Há graus de supremacia e nunca ruptura absoluta entre os opostos no jogo heraclitiano de liberdade-poder. $\mathrm{O}$ circuito permanece com suas determinações de mão-dupla, mas curtos-circuitos podem ocorrer nos excessos de poder e nos deslocamentos insubmissos e subversivos da liberdade. Ora o poder prevalece e se encaminha para a cristalização violenta da dominação, ora a liberdade destoa 0 estabelecido, o naturalizado, as verdades e as normas, pungente em sua fissura desmedida e transgressiva, latente no dizível, mas ainda pouco ou nada inteligível. O corpo floresce com o novo, uma nova vida se encarna como modo de vida, uma nova subjetivação, prazeres inauditos. A liberdade é criação não do nada, mas a partir das restrições.

A liberdade é o limite do poder na medida em que é o limite da norma e do inteligível. O poder normatiza e torna as existências inteligíveis, reconhecíveis para si e para o outro. A liberdade, por outro lado, embaralha a ordem, o status quo, subvertendo as normas e transgredindo os sentidos já estabelecidos culturalmente. A liberdade é vivida como experiência de transformação profunda, na medida em que rompe com as normas que determinam o reconhecimento de si como um sujeito de tal ou tal tipo na sociedade. Escapar inteiramente ao dispositivo é impossível, mas reduzi-lo, modificá-lo, subvertê-lo é possível e depende de o indivíduo colocar a si mesmo em xeque. Por um lado, o indivíduo se constitui como sujeito de sexualidade ao introjetar como naturais verdades dadas socialmente, pois que se habitua a acreditar e a agir conforme tais verdades, classificações, regras de conduta, prescrições que lhe são atribuídas nas e pelas instituições de poder; por outro lado, o indivíduo se constitui enquanto praticante de uma sexualidade livre ao resistir às verdades naturalizadas pelas relações de poder e isso, sobretudo, por meio de práticas que rompem as normas reguladoras da sexualidade. 
Butler, em Problemas de Gênero, mostrou que o binarismo é quebrado e subvertido com a multiplicação de gêneros, evidenciando assim que gênero é um constructo social e não um dado natural. Esse parece ser o mesmo caminho indicado por Foucault quando ele diz que o contra-ataque são os corpos, os prazeres e os saberes "em suas multiplicidades e possibilidades de resistência" (FOUCAULT, 2007a). Viver a sexualidade com liberdade significa multiplicar as experiências-limites dos corpos e dos prazeres para além do que se preconiza como natural ou normal no atual regime de verdade de nossa sexualidade. Ou seja, multiplicar as experiências de desejo, prazer e expressividades do corpo nas relações sexuais, abrindo-se para o não dado, o não dito, o não estabelecido, o não naturalizado ou normatizado, significa não apenas questionar os regimes de verdade que permeiam a sexualidade, mas romper na pele com tais regimes, beirar o ininteligível, transgredir as normas, subverter o poder. Para tanto, a condição para se viver a sexualidade com maior liberdade depende de as relações sexuais serem vividas do modo mais livre possível, ou seja, em que o jogo poder-liberdade entre os parceiros sexuais seja o mais flexível, múltiplo e aberto possível. Eis o que podemos entender por sexualidade livre à luz de Foucault. 


\section{Referências:}

BUTLER, J. Problemas de gênero: Feminismo e subversão de identidade, Rio de Janeiro: ed. Coleção Brasileira, 2016.

BUTLER, J. A vida psíquica do poder: Teorias da sujeição, Belo Horizonte: ed. Autêntica, 2017.

BUTLER, J. Revisiting Bodies and Pleasures. In: Theory, Culture \& Society (SAGE, London, Thousand Oaks and New Delhi), Vol. 16 (2): 11-20, 1999.

CASTRO, E. Vocabulário de Foucault: um percurso pelos seus temas, conceitos e autores. Trad. I. M. Xavier. Belo Horizonte: ed. Autêntica, 2011.

CASTRO, E. Introdução a Foucault. Trad. B. de A. Magalhães. Belo Horizonte: ed. Autêntica, 2014.

DELEUZE, G. Focault. Paris, Editions de Minuit, 2004. [Foucault.

Trad. C. S. Martins. São Paulo, Brasiliense, 2005].

DUARTE, A. e CÉSAR, M. Inútil resistir ao dispositivo de sexualidade? Foucault e Butler sobre corpos e prazeres. Rev. Filos., Aurora, Curitiba, v. 28, n. 45, p. 949-967, set./dez. 2016.

DUARTE, A. Reler Foucault à luz de Butler: repensar a Biopolítica e o Dispositivo da Sexualidade. Dois Pontos: Curitiba, São Carlos, volume 14, número 1, p. 253-264, abril de 2017.

FOUCAULT, M. História da sexualidade I: A vontade de saber. Trad. de Maria Albuquerque. Rio de Janeiro: ed. Graal, 2007a.

FOUCAULT, M. História da Sexualidade II: O uso dos prazeres. Trad. de Maria Albuquerque. Rio de Janeiro: ed. Graal, 2007b.

FOUCAULT, M. História da Sexualidade III : O cuidado de si. Trad. de Maria Albuquerque. Rio de Janeiro: ed. Graal, 2007c.

FOUCAULT, M. Sexo, Poder e a Política da Identidade (1982). In: Motta, M. (org.) Ditos e escritos IX. Rio de Janeiro: Forense Universitária, 2014a, p.251-263.

FOUCAULT, M. A ética do cuidado de si como prática da liberdade (1984): In: Motta, M. (org.) Ditos e escritos V. Rio de Janeiro: Forense Universitária, 2017, p. 258-280.

FOUCAULT, M. Sexualidade e Política (1978): In: Motta, M. (org.) Ditos e escritos V. Rio de Janeiro: Forense Universitária, 2017, p. 25-35.

FOUCAULT, M. O sujeito e o poder (1982). In: Motta, M. (org.) Ditos e escritos IX. Rio de Janeiro: Forense Universitária, 2014a, p. 118-140.

FOUCAULT, M. Poder e corpo (1975). In: Motta, M. (org.) Ditos e escritos X. Rio de Janeiro: Forense Universitária, 2014b, p. 258-264. 
FOUCAULT, M. "Introduction" to Herculine Barbin. Nova York: Pantheon, 1980.

FOUCAULT, M. Herculine Barbin dite Alexina B. Paris: Gallimard, 2014.

FOUCAULT, M. O saber gay. In: Ecopolítica n. 11, jan./abr. 2015. Trad. Éder Amaral e Silva e Heliana de Barros Conde Rodrigues.

OSKALA, J. Foucault on freedom. UK: Ed. Cambridge University Press, 2005.

REVEL, J. Foucault Conceitos Essenciais. Trad. Sob a direção de Carlos Piovezani Filho e Nilton Milanez. São Carlos: Editora Claraluz, 2005. 96p.

SAFATLE, V. Para além da sexualidade: Foucault e a Liberdade como autopertencimento. In: NOVAES, A. (org.) Mutações: entre dois mundos. São Paulo: ed. Sesc, 2017, pg. 345-369.

Errata:

Nas p. 115, linha 12, p. 127, linha 31 e p. 130, linha 6, onde se lê "cheque", leia-se "xeque".

Sempre onde consta "Oskala", leia-se "Oksala". 